\title{
Strength Properties of Porcelain Admixed Concrete
}

\author{
${ }^{1}$ Noor Faisal Abas, ${ }^{2}$ Khairusy Syakirin Norizan, ${ }^{3}$ Zakariah Abd Ghani
}

\begin{abstract}
The use of concrete in construction industry and in development is important and concrete is the most necessary material which is widely used in the world. The concrete consist of coarse aggregate, sand and cement as binder materials. This study consists of experimental on the impact of using porcelain use as cement replacement materials to produce a new product of concrete. The experiment will be figure out through mechanical performance of concrete. The mix percentage of porcelain uses are 5\%, 15\% and $30 \%$ of replacement cement materials and the concrete admixtures is fixed in optimum amounts. All specimens are cured in the water until it reaches the right age to be tested. The specimens will be tested at the age of 7, 14, 21 and 28 days. The mechanical performance of this material is determined through compressive strength, flexural strength, PUNDIT, slump and bulk of density test and to be compared with control mix specimen which is the $100 \%$ of concrete specimen.
\end{abstract}

Keywords - porcelain, cement replacement material, compressive strength, flexural strength, PUNDIT, slump, bulk of density

\section{INTRODUCTION}

The demand of concrete nowadays is high due to the increasing of the development rate and construction industry. High production of cement will affect the reduction of the limestone sources on the earth. Besides that, uncontrolled production of cement in cement industries will cause the environmental affect such as carbon dioxide emission and greenhouse emissions. Sustainability in construction is currently a major concern, given the important environmental, social and economic impacts of this industry, and cement consumption should be one of the principal considerations when manufacturing materials. [1]

In developing country like Malaysia, the government had started to promote a new concept of construction which concern of sustainability construction such as green building campaign in order to reduce the effect of air pollution. Based on the facts, about $30 \%$ of carbon dioxide emissions and about $3000 \mathrm{Mt} /$ year of raw materials consuming which affect the depletion of large amounts of nonrenewable resources. This fact stated why the construction industry can be considered as unstable industry in terms of sustainability. [2]. the concrete abilities which are its strength being able to support bigger load and their durability against the environment had made the material became the important material in construction

\footnotetext{
${ }^{1,2,3}$ School of Housing, Building and Planning, Universiti Sains Malaysia 11800, Penang, Malaysia

${ }^{1}$ ksyakirin1@gmail.com,2nfaisal@usm.my,3 zag_5737@yahoo.com
}

industry. However, uncontrolled production of the materials will be one of the negative effects on our environment.

Previous studies had being carried out in order to reduce the dependency on cement by replacing other materials into concrete. The replacement materials that being used to reduce the dependency in concrete such as fly ash, silica fume, clay, glass and many more. Based on the studies, these materials are proven have a binder characteristics compared to cement and they are environmental friendly. The use of raw porcelain as the alternative material to replace cement will reduce the dependency on cement. This material will affect the strength and the durability of the concrete compared to the original concrete.[1] Another research that being conducted by using another materials that have quite similar properties with porcelain also being tested to replace cement in concrete by using metakaolin. Metakaolin is an effective pozzolan and the results of the research shows of the improvement in the early strength and in the long term strength. Besides that, Metakaolin consume in the improvement of the resistance to the transportation of water in concrete [3]. Another research conducted is by using waste brick. According to the result, waste brick can be used up to $10 \%$ as a replacement of cement in production of cement mortar [4]. By using ground dune sand as replacement materials shows the maximum compressive strength was achieved at $30 \%$ level of replacement [5]. Another research conducted was to investigate the influences of different percentage waste concrete ash as cement replacement material. The result shows that the increase of waste concrete ash in percentage of cement replacement will cause a loosening between the binders and aggregate and lowering the compressive strength [6]. The clay wastes that containing boron additives were mix with Ordinary Portland Cement (OPC) and were tested in differences proportion of percentages to replace the cement. The results show that the clay waste can be used in cement, mortar or concrete as an additive up to $5 \%$ of cement with comparable or better performance than OPC [7].

Besides that, there are other materials that also being used as a cement replacement material in concrete and the results of the test being analyzed. For example,by replacing cement with the wood ash. By replacing cement does not give negative implication on chloride permeability. Water absorption will be increased when the wood ash percentage is increasing [8]. Lastly, is silica fumed. From the research that being done before, the overall durability of concrete is being improved when this materials is used. $25 \%$ of silica fume had being replace with the Portland cement (the SF coarse sieved into 45 $\mathrm{lm}$ sieve residue of $4.13 \%$ and $0.98 \%$ ) produce of high 
strength mortar and the SF fineness consume the higher compressive strength. The Silica Fume with high fineness is preferable pozzolanic material which can be used in order to produce a high performance concrete. [9].

\section{MATERIAL}

\section{A. Cement}

The cement used for the study is an Ordinary Portland Cement (OPC) from Cement Industries of Malaysia Berhad (CIMA Group). The cement is classified as MS 522, as well as in BS EN 196.

\section{B. Fine Aggregate}

Fine aggregate are sands from the land or the marine environment. Fine aggregates generally consist of natural sand or crushed stone with most particles passing through $4.75 \mathrm{~mm}$ sieve. Aggregates are granular materials that required along with water and Portland cement for the production of a concrete. Aggregates strongly influence concrete's freshly mixed and hardened properties, mixture proportions, and economy. The composition of fine aggregate is containing about $90 \%$ of silicon oxides. The other compositions are aluminum oxides, calcium oxides and others.

\section{Water}

Water are used in concrete mixture to wet the surface of aggregates to develop adhesion because the cement pastes adheres quickly and satisfactory to the wet surface of the aggregates than to a dry surface. Water is also needed for the hydration of the cementing materials to set and harden during the period of curing.

Limiting and controlling t he amount of the water in concrete is necessary for the constructability and service life. Besides that, the amount of water use in concrete will affect in many fresh and hardened properties of concrete. For example, the amount of water use controls in workability, compressive strength, permeability, durability, drying shrinkage and potential for cracking.

\section{Porcelain}

Porcelain is a material that is produce from the heating materials in a kiln at temperatures from 1200 to 1400 degree. Ceramic tiling which is the product from the porcelain materials is widely used in the construction industry. Based on the previous research, the production process of tiles produces porcelain polishing residue (PPR). PPR was the main residue in the sludge with loss rates above $1 \%$. Because it is impure waste, its end up being discarded in landfills.

However, considering its characteristics, its fineness and chemical composition, its potential as a pozzolanic material was evaluated for use in the manufacture of cement-based construction materials in order to improve concrete durability and strength. In this research, Porcelain is grinded by using a machine in a laboratory to produce smooth particles of the materials. Raw porcelain with different percentage of weight is replace in the cement content while the weight of other materials are fixed.

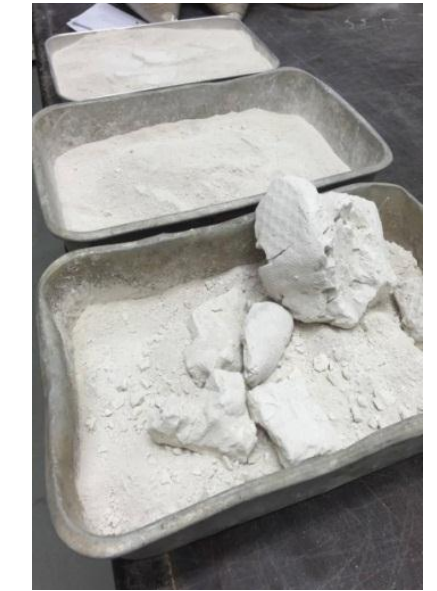

Fig. 1: Image of the Porcelain material

\section{E. Coarse Aggregate}

In this research, a coarse aggregate being used was $20 \mathrm{~mm}$. Coarse aggregates with sizes of $20 \mathrm{~mm}$ was the suitable size. For coarse aggregates at maximum $40 \mathrm{~mm}$ coarse aggregates are can be used in concrete that has no restrictions to flow and for sized of $10 \mathrm{~mm}$ it is suitable used for the concrete elements with thin size such as wall partitions. They were sieve through $20 \mathrm{~mm}$ sieved apparatus.

Based on ASTM C 33, "Standard Specifications for Concrete Aggregates", good quality aggregates must have some characteristics which are clean, hard strong, consist of durable particles and be free of absorbed harmful chemicals and other contaminates that can affect hydration of cement or reduce the paste - aggregate bond. Proper selection of aggregates by selecting the maximum allowable aggregate size will help in saving money. By choosing a large size of coarse aggregate will helps in reducing the cost of concrete mix by reducing the cement requirements which is the costly ingredient. Less cement use within acceptable limits for durability, means less water needed (if the water cement ratio is constant). Lower water content will reduce the possible of shrinkage and cracking and related to the restrained volume change. [10].

\section{EXPERIMENTAL PROGRAM}

There were 4 types of mixes in this study with grade 20 of concrete and had 4 different percentage of cement replacement. It made the total mix to $3 \mathrm{mix}$ cement replacement concrete and $1 \mathrm{mix}$ of control. All mixes were produced by tilting a drum mixer. All of the materials including sand, coarse aggregates, cement, and porcelain are mixed in the drum mixer and let it mix about 3 minutes. The water will be added into the mixer and continued mixing for another 2 minutes.

After uniformly mixed, the mixture will be placed into the mould with size of $100 \times 100 \times 100$ (cube) and $100 \times 100$ X 500 (prism). The mixture will be placed on 3 equal layers on the vibrating table and was vibrated for 10 seconds of each layer. The samples will be demoulded on the next 24 hours and the specimens will be placed in the water tank for curing process. The specimens will be stored until testing days. 
TABLE I: MIX DESIGN FOR THE RESEARCH

\begin{tabular}{|l|l|l|l|}
\hline Materials (kg) & $5 \%$ & $15 \%$ & $30 \%$ \\
& & & \\
\hline Water & & & \\
\hline Fine Aggregates & & & \\
\hline Coarse Aggregates & 11.36 & 11.36 & 11.36 \\
\hline Cement & 44.13 & 44.13 & 44.13 \\
\hline Porcelain & 69.07 & 69.07 & 69.07 \\
\hline
\end{tabular}

IV. RESUlTS AND DiscUSSION

\section{A. Compressive Strength}

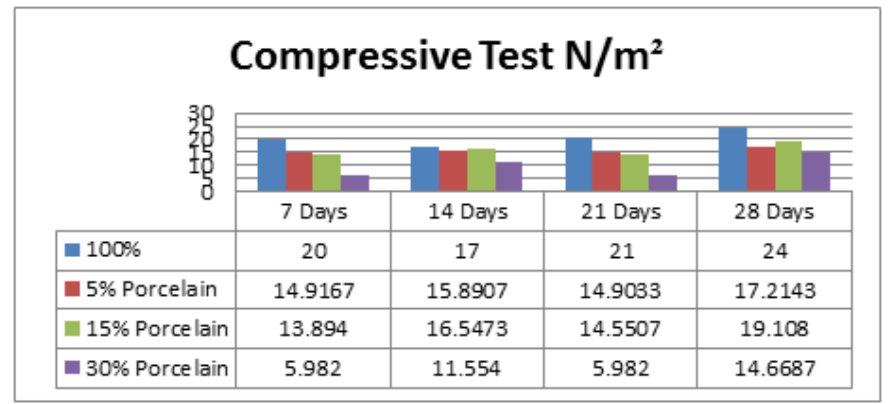

Fig. 1: Compressive Strength

Figure 1 shows the result of compressive strength test of the concrete specimen. Compressive test was conducted for 28 days. Figure 1 shows the results of the compressive test of the specimens that contain additional cement admixture as cement replacement in concrete and were compared to the original mixture in grade 20. In generally, the result shows the compressive strength of the specimens that contain replacement materials is lower than the compressive strength of controlled specimen which is $100 \%$ mix. The specimens containing of replacement material can't achieved the target strength of the concrete which is grade 20 concrete. The highest strength of the specimen can be reached is $19.108 \mathrm{~N} /$ $\mathrm{m}^{2}$ through the specimen that contain $15 \%$ of porcelain at the age of 24 days.

\section{B. Flexural Strength}

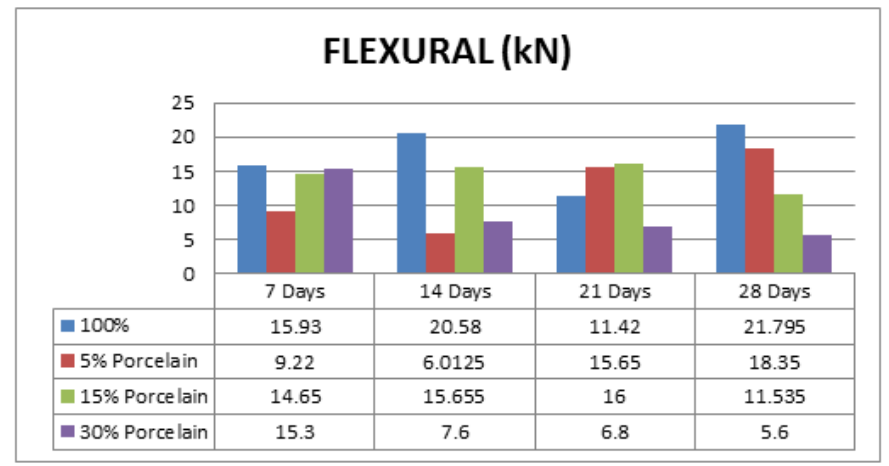

Fig. 2: Flexural Strength

Figure 5 shows the flexural strength result from the tests carried out on the concrete specimens. Based on the figure, the control mix $(100 \%)$ recorded a flexural strength of $15.93 \mathrm{MPa}$ at the age of 7 days and increase to $21.795 \mathrm{MPa}$ of strength at the age of 28 days. The same pattern shows on the other specimens using of Porcelain at different percentages in their mix. For $5 \%$ containing of Porcelain specimen, recorded of 9.22 $\mathrm{MPa}$ at the age of 7 days which is the lowest strength compared to other specimens at the age of 7 days. The strength keeps decreasing at the age of 14 days which is $6.0125 \mathrm{MPa}$ also the weakest strength compared to the other specimens. At the age of 21 days the strength increases to $15.65 \mathrm{MPa}$ which is higher than control mix and keeps increasing to $18.35 \mathrm{MPa}$. For mix containing $15 \%$ of porcelain recorded $14.65 \mathrm{MPa}$ and increases to $15.655 \mathrm{MPa}$ at the age of 14 days and $16 \mathrm{MPa}$ at the age of 21 days. However, the strength is decreases to $11.535 \mathrm{MPa}$ at the age of 28 days. Mix of $30 \%$ containing Porcelain, shows inversely proportional pattern from the age of 7 days to 28 days. For the result of 7 days recorded $15.3 \mathrm{MPa}$, 7.6 $\mathrm{MPa}$ at 14 days, $6.8 \mathrm{MPa}$ at 21 days, and $5.6 \mathrm{MPa}$ at the age of 28 days.

\section{Bulk of Density}

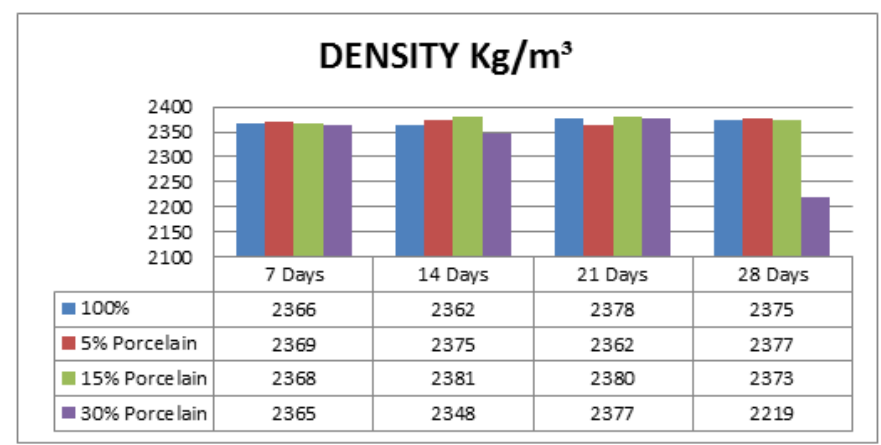

Fig. 3: Bulk Density (prism)

Figure 4 above shows the result bulk of density test (prism) that had made in this research. The test had being conducted for 28 days. Based on the figure, the highest of data collected is $2366 \mathrm{~kg} / \mathrm{m}^{3}$ and the lowest is $2219 \mathrm{~kg} / \mathrm{m}^{3}$. The target of average bulk density test on the specimen was $2400 \mathrm{~kg} / \mathrm{m}^{3}$. However, there are some of the specimens which are recorded the result higher and lower compared the control mix (100\%). There is a reason that affect the result of the specimen which is due to the reduction of the of the cement specimen is influence with the density of porcelain that being replace with cement that contributed to compacted microstructure.

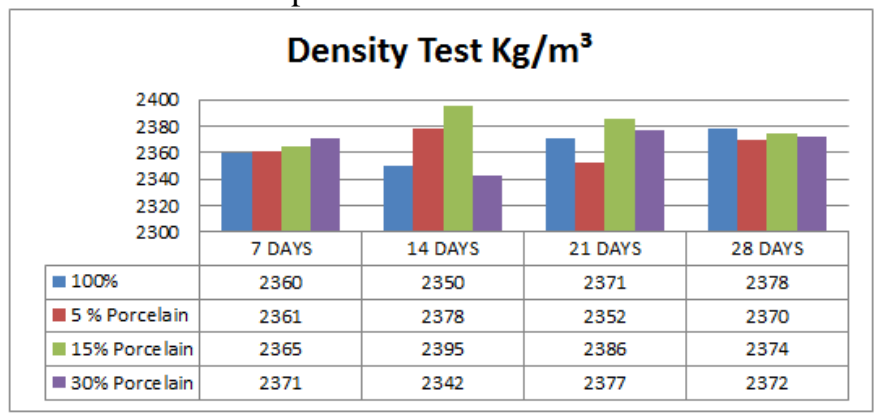

Fig. 4: Density (cube)

Figure 5 shows the result of bulk density test (cube) that had made in this research in 28 days. Based on the figure, the highest data collected is $2395 \mathrm{~kg} / \mathrm{m}^{3}$ while the lowest is 2342 
$\mathrm{kg} / \mathrm{m}^{3}$. The target of average bulk density test on the specimen was $2400 \mathrm{~kg} / \mathrm{m}^{3}$. There are some of the specimens which are recorded the result higher and lower compared the control mix $(100 \%)$. There is a reason that affect the result of the specimen which is due to the reduction of the of the cement specimen is influence with the density of porcelain that being replace with cement that contributed to compacted microstructure.

The overall result show the pattern of the data collected which is there are up and down of the result between 7 days until 28 days. Therefore, by using porcelain as a cement replacement material will affect the increasing and decreasing of the density of the concrete. The highest density of the concrete is $2395 \mathrm{~kg} / \mathrm{m}^{3}$ at $15 \%$ porcelain on 14 days.

\section{Ultrasonic Pulse Velocity}

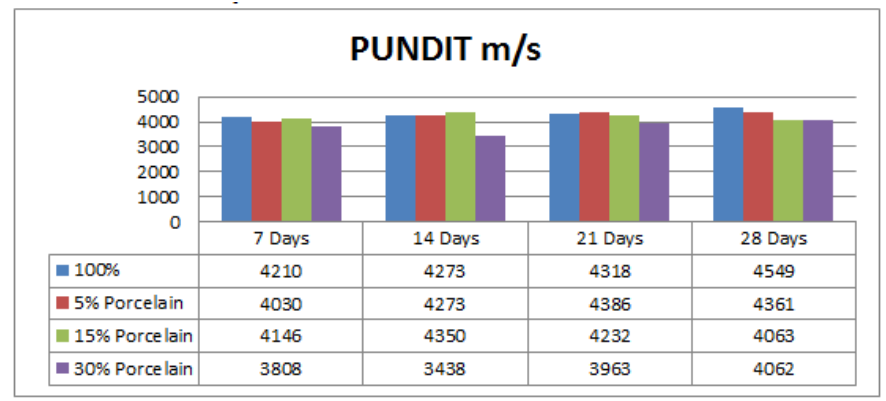

Fig. 5: Ultrasonic Pulse Velocity (prism)

Figure 6 shows the data collected of PUNDIT test of the specimens (prism) on 28 days. Based on the results, the highest data recorded is $4549 \mathrm{~m} / \mathrm{s}$ which is on control specimen at 28 days, while the lowest is $3438 \mathrm{~m} / \mathrm{s}$ on $30 \%$ porcelain at days. The result of controlled mix shows the increasing pattern from the age of 7 days which is $4210 \mathrm{~m} / \mathrm{s}$ until the age of 28 days which the data recorded $4549 \mathrm{~m} / \mathrm{s}$. While on 5\% Porcelain specimen, shows the increasing from the age of 7 days, $4030 \mathrm{~m} / \mathrm{s}$ until at the age of 21 days, 4386 $\mathrm{m} / \mathrm{s}$ and decrease at the age of 28 days, with the value 4361 $\mathrm{m} / \mathrm{s}$. On $15 \%$ of Porcelain mix, shows the increasing at the age 7 days, $4146 \mathrm{~m} / \mathrm{s}$ until the age of 14 days, $4350 \mathrm{~m} / \mathrm{s}$. At the age of 21 until the age 28 , there is the decreasing which is the result fall from $4232 \mathrm{~m} / \mathrm{s}$ to $4063 \mathrm{~m} / \mathrm{s}$. For the $30 \%$ porcelain specimen, decrease from $3808 \mathrm{~m} / \mathrm{s}$ to $3438 \mathrm{~m} / \mathrm{s}$. At the age of 21 days, the data recorded is $3963 \mathrm{~m} / \mathrm{s}$ and at the age of 28 days is $4062 \mathrm{~m} / \mathrm{s}$ which represent the increasing pattern at the age 21 days until 28 days.

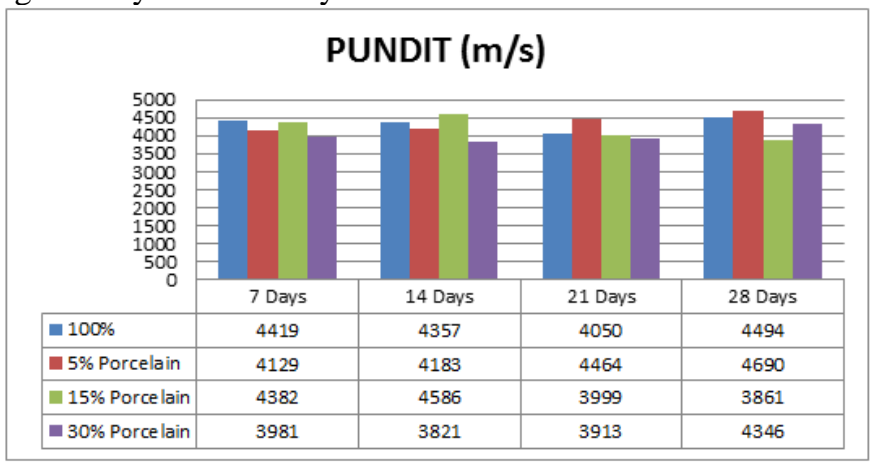

Fig. 6: Ultrasonic Pulse Velocity (cubes)
Figure 7 represent the results of PUNDIT test of the specimens (cube) on 28 days. It shows that the pattern of the result of each specimen have a different in terms of the pulse velocity values. The pulse velocity of the control mix (100\%) in 7 days decrease from $4419 \mathrm{~m} / \mathrm{s}$ to $4357 \mathrm{~m} / \mathrm{s}$ at 14 days, and $4050 \mathrm{~m} / \mathrm{s}$ at the age of 21 days. The highest value of pulse velocity for control mix is $4494 \mathrm{~m} / \mathrm{s}$ which were recorded at the age of 28 days with the value $4494 \mathrm{~m} / \mathrm{s}$. For the specimen containing $5 \%$ of Porcelain shows the increasing pattern from the age of 7 days until the age of 28 days which is $4129 \mathrm{~m} / \mathrm{s}$, increase to $4183 \mathrm{~m} / \mathrm{s}$, to $4464 \mathrm{~m} / \mathrm{s}$ and the highest value recorded is $4690 \mathrm{~m} / \mathrm{s}$ at the age of 28 days which is the highest value of the test. For the specimen containing of $15 \%$ porcelain, the value at the age of 14 days increased from 4382 $\mathrm{m} / \mathrm{s}$ at the age of 7 days to $4586 \mathrm{~m} / \mathrm{s}$. However, the value decreased at the age of 21 days to $3999 \mathrm{~m} / \mathrm{s}$ and keeps decreasing to $3861 \mathrm{~m} / \mathrm{s}$ at the age of 3861 days. For the $30 \%$ of Porcelain specimen also decreasing from $3981 \mathrm{~m} / \mathrm{s}$ at the age of 7 days into $3821 \mathrm{~m} / \mathrm{s}$ at 14 days. At the age of 21 days, the value is increasing from $3913 \mathrm{~m} / \mathrm{s}$ to $4346 \mathrm{~m} / \mathrm{s}$.

\section{DISCUSSION}

From the results obtained, the following conclusion can be drawn:

- The increasing of cement replacement materials does enhance the compressive strength of the concrete. However, the improvement only occur on $15 \%$ of replacement which the result of the specimen containing $15 \%$ of replacement porcelain at the age of 28 days is almost reach the value of the target concrete, $20 \mathrm{~N} / \mathrm{m}^{2}$. The value of compressive strength of $30 \%$ replacement is decreasing, this is because, more porcelain added in concrete to be substitute with cement will decrease the value of compressive strength of the concrete.

- For the flexural strength, the highest strength of the replacement specimen is $5 \%$ porcelain, $18.35 \mathrm{kN}$ at the age of 28 days compared to the control mix (100\%) is 21.795 $\mathrm{kN}$. At the age of 28 days. The replacement of porcelain will affect the reduction of flexural strength compared to the control mix. The highest the percentages of replacement will decrease the value of flexural test.

- The density for cube and prism of porcelain as cement replacement in concrete specimens is higher than control mix $(100 \%)$ even though could not reach the target of 2400 $\mathrm{kg} / \mathrm{m}^{3}$. Based on the result, the specimens containing porcelain recorded the results close to the level of the control mix specimens and close to the density target. Therefore, it may be a possibility to have the results that successfully match the control mix specimens in bulk of density performance. 


\section{ACKNOWLEDGEMENT}

The authors would like to thank the funding bodies of this research: Ministry of Higher Education Malaysia (MOHE) under FRGS Grant. No. 203/PPBGN/6711516.

\section{REFERENCES}

[1] (Jacoby \& Pelisser 2015) Pozzolanic effect of porcelain polishing residue in Portland cement

[2] (Ali Akbar Ramezanianpour,Materials 2014) Cement Replacement Materials

[3] (B. Sabir, S. Wild, J. Bai 2001) Metakaolin and calcined clays as pozzolans for concrete

[4] (Naceri, A. and Hamina, M.C., 2009) Use of waste brick as a partial replacement of cement in mortar. Waste Management, 29 (8), 23782384.

[5] (Negheimish, A., and Noorzaei, J., 2014). Use of fine ground dune sand as a supplementary cementing material. Journal of Civil Engineering and Management, 20 (1), 32-37.

[6] (Husain, A.H. and Abas, N.F., 2015). The Mechanical Performance of Waste Concrete Ash as Cement Replacement Materials in Concrete. AMM Applied Mechanics and Materials, 747, 234-237

[7] (Özdemir, M. and Uğurlu, A., 2011). Evaluation of Boron Containing Clay Wastes in Cement Production. Materials and Manufacturing Processes, 26 (9), 1130-1135.

[8] (Chowdhury, Swaptik Mishra, Mihir Suganya, Om, 2015) The incorporation of wood waste ash as a partial cement replacement material for making structural grade concrete.

[9] (Ángel, Miguel Argiz, Cristina Gálvez, Jaime C Moragues, Amparo 2015) Effect of silica fume fineness on the improvement of Portland cement strength performance

[10] (George Seegebrecht, The Role Of Aggregate In Concrete (http://www.concretenetwork.com/aggregate/) 